\title{
Diffusion weld study for Test Blanket Module fabrication
}

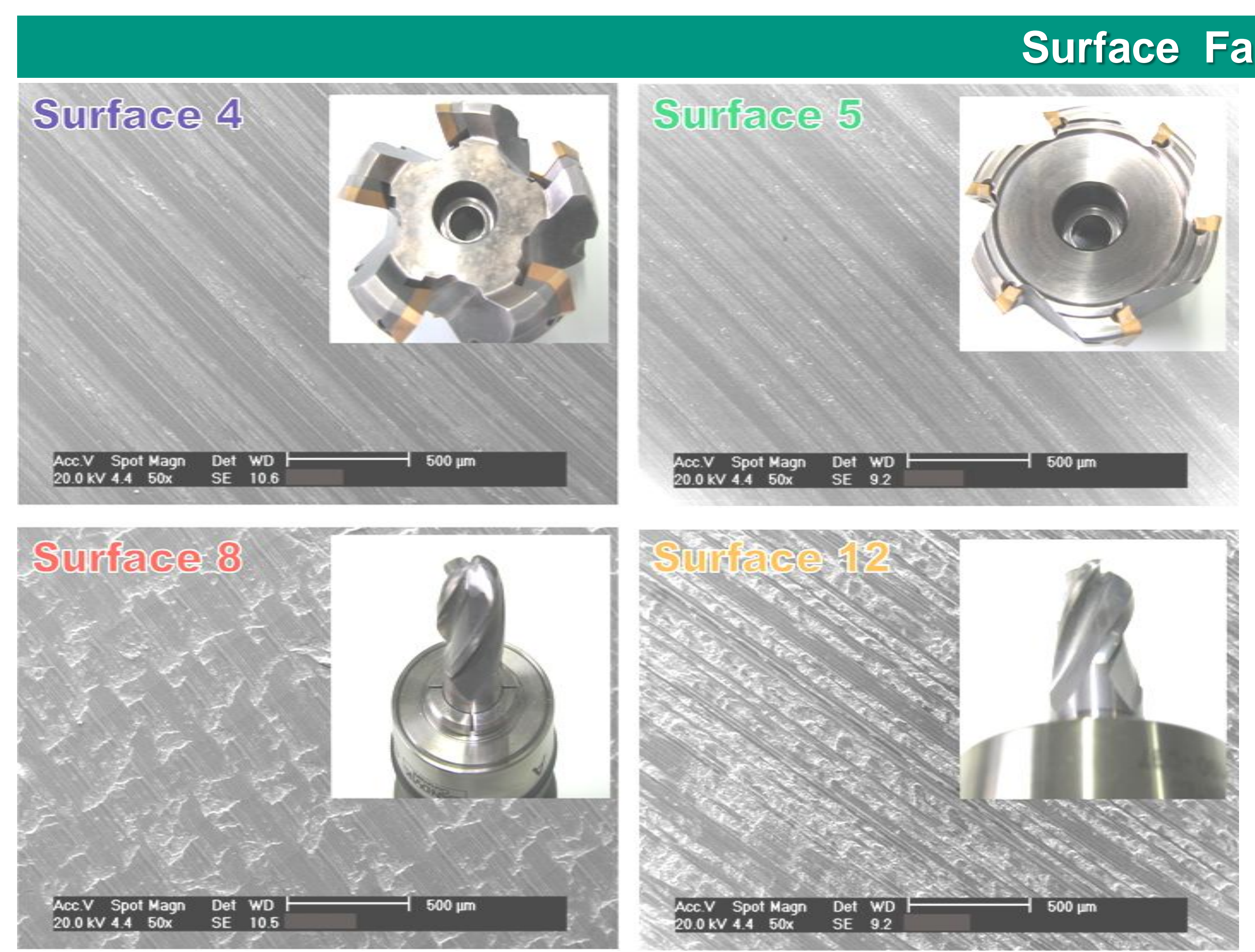

(1) Depending on tools and fabrication parameters, surface structures may be quite different, even though their roughness is in the same range (here $\pm 0.6 \mu \mathrm{m}$ ).
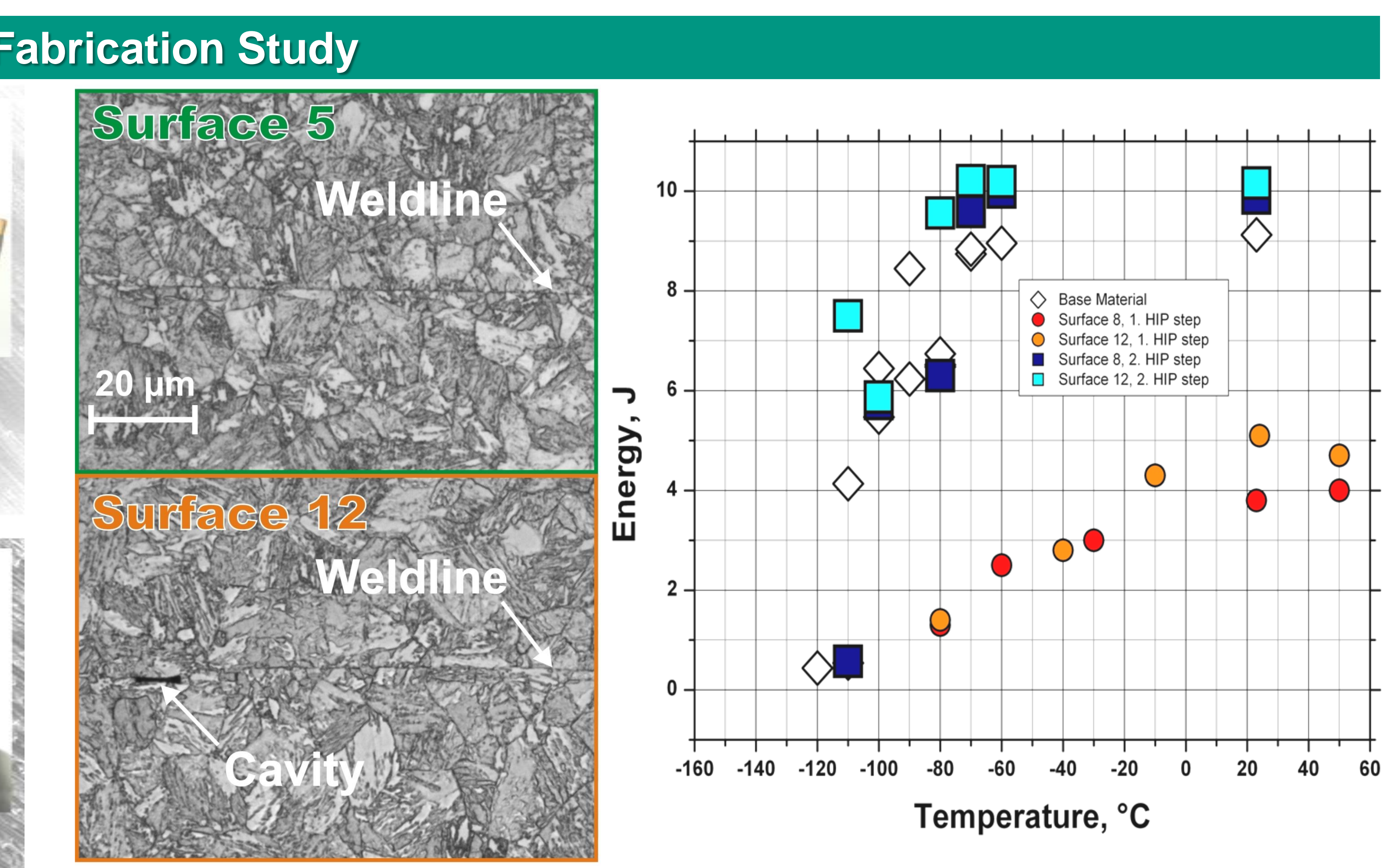

Temperature, ${ }^{\circ} \mathrm{C}$

(2) Depending on the surface structure, more or less cavities remain after diffusion welding at low pressure $\left(1050^{\circ} \mathrm{C}, 25 \mathrm{Mpa}, 2 \mathrm{~h}\right)$ with vacuum sealing. Remaining cavities at the weld interface lead to reduced Charpy properties. But weld defects may be restored by applying a second high pressure HIP step $\left(1050^{\circ} \mathrm{C}, 100 \mathrm{Mpa}, 2 \mathrm{~h}\right)$ without vacuum sealing.

\section{Surface Contamination Study}

Surface 20: Reference fabrication (dry milling with optimised parameters and immediate sealing by EB-welding) Surface $21,22,23,24: 1,2,3,14$ days at $70 \%$ relative humidity before sealing

Surface 25: Surface protection with oil, 14 days at $70 \%$ relative humidity, cleaning with isopropanol before sealing

Surface 26: Surface protection with oil, 14 days at $70 \%$ relative humidity, cleaning with soap before sealing

Surface 28: Surface fabrication with optimised parameters, but milling with industrial standard coolant, just dried before sealing Surface 29: as Surface 28, but cleaning with isopropanol before sealing

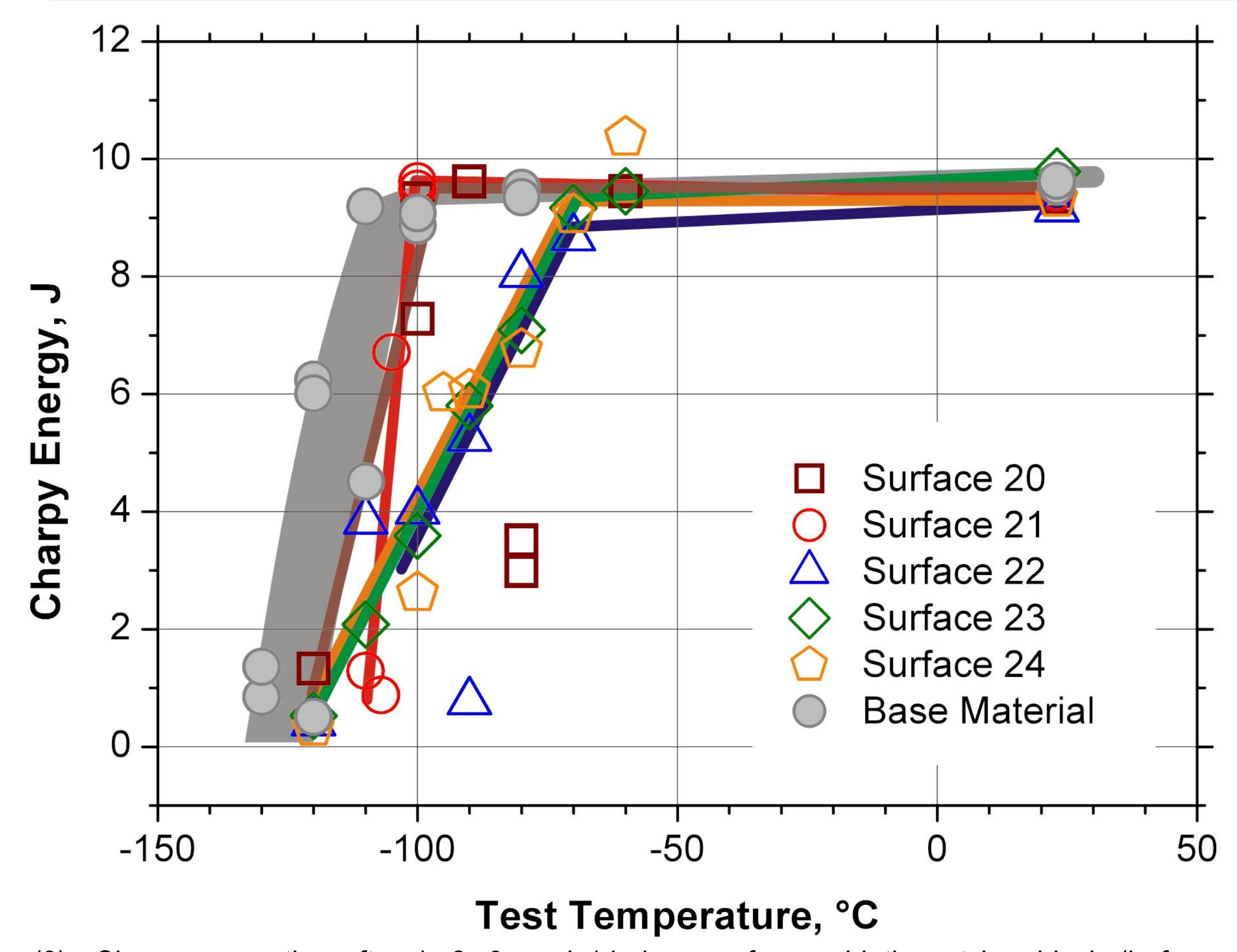

(3) Charpy properties after 1, 2, 3, and 14 days surface oxidation at humid air (before welding at $1150{ }^{\circ} \mathrm{C}, 25 \mathrm{MPa}, 2 \mathrm{~h}$ ). After 2 days oxidation in humid air DBTT is clearly deteriorated. However, there is no loss of upper shelf energy, but some severe scattering results have been observed, even for the reference fabrication process.
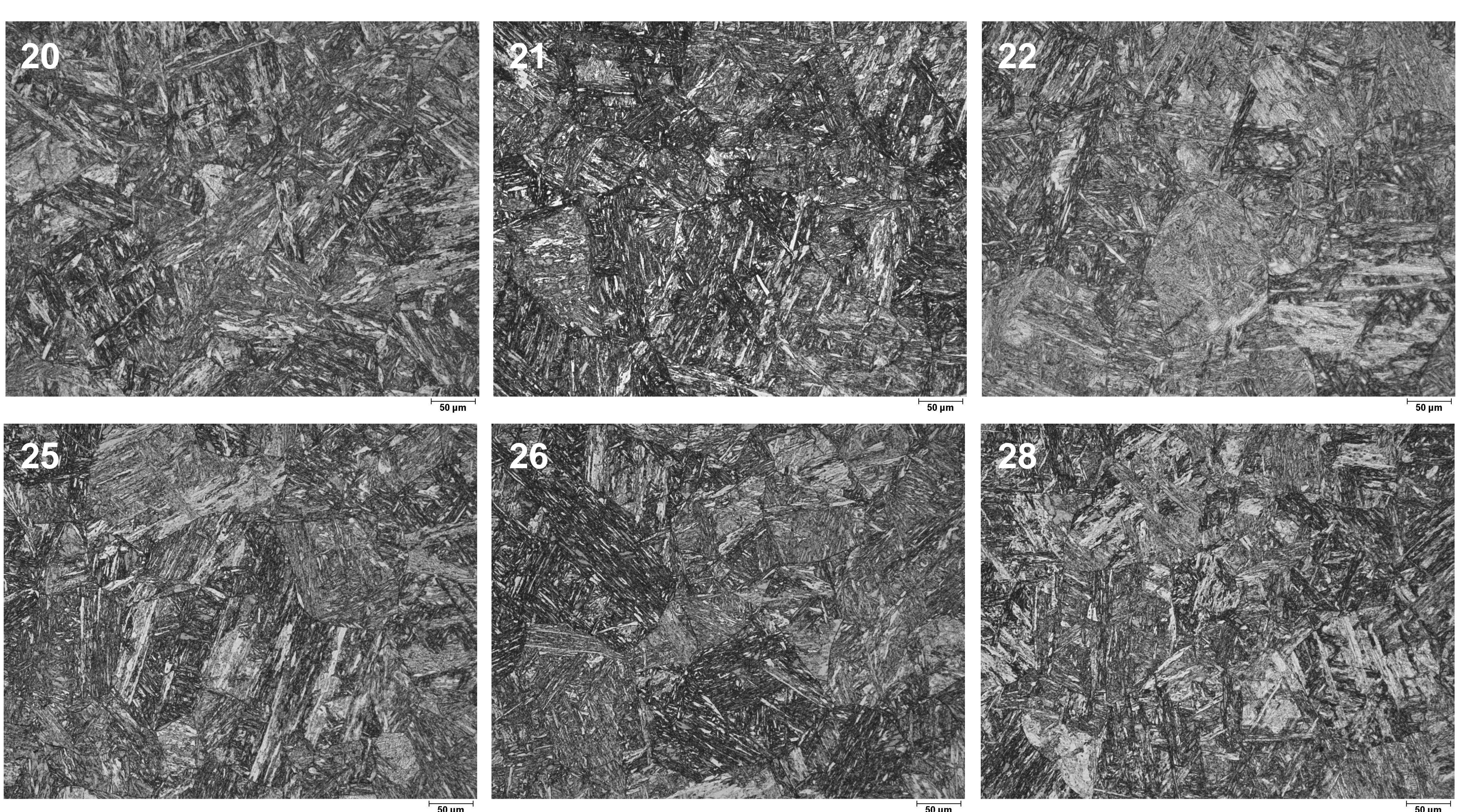

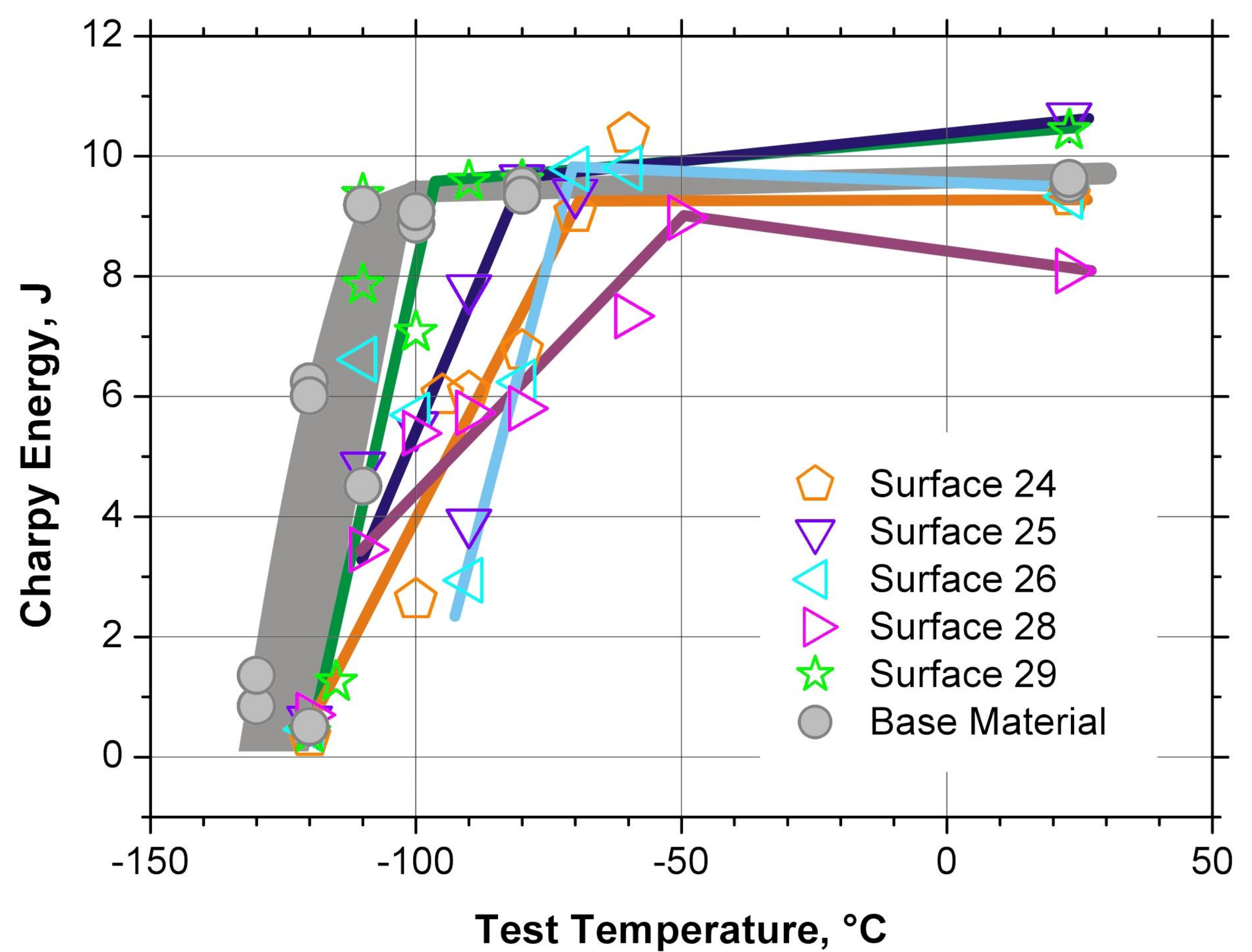

(4) Charpy properties after different wetting and cleaning procedures (before welding at $1150^{\circ} \mathrm{C}, 25 \mathrm{MPa}, 2 \mathrm{~h}$ ). Best results are achieved after milling with coolant and cleaning with isopropanol. Furthermore, oil is obviously not a useful protector against oxidation.
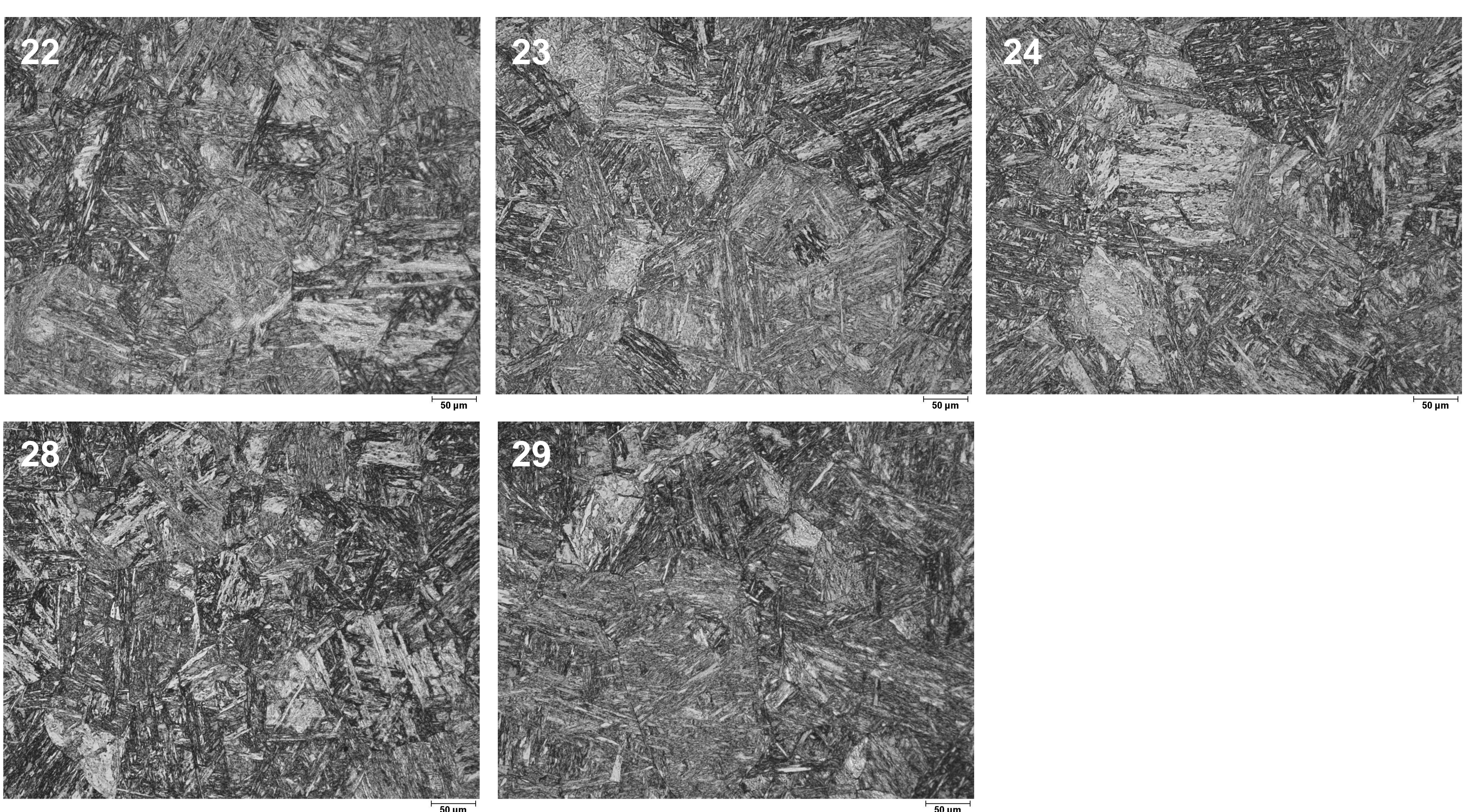

(5) The micrographs of all weld interfaces show now weld line. That is, from a micro-structural point of view the diffusion welds (peformed at $1150{ }^{\circ} \mathrm{C}$, under $25 \mathrm{MPa}$, for 2 hours) are all perfect, regardless of the fabrication history. The above shown Charpy test results, however, demonstrate that there are differences, anyway.

${ }^{1}$ Forschungszentrum Karlsruhe GmbH, IMF I, P.O. Box 36 40, 76021 Karlsruhe, Germany, " michael.rieth@imf.fzk.de 